\title{
A CASE OF TRISOMY 21 WITH HOLOPROSENCEPHALY: THE FIFTH CASE
}

\author{
Hiromi Hamada, ${ }^{1}$ Tadao Arinami, ${ }^{2}$ Mitsuhiko Koresawa, ${ }^{1}$ \\ Takeshi Kubo, ${ }^{1}$ Hideo Hamaguchi, ${ }^{2}$ and Hirokazu IwasakI ${ }^{1}$ \\ ${ }^{1}$ Department of Obstetrics and Gynecology, Institute of Clinical Medicine and \\ ${ }^{2}$ Department of Human Genetics, Institute of Basic Medical Sciences, \\ University of Tsukuba, Tsukuba, Ibaraki 305, Japan
}

\begin{abstract}
Summary A case of trisomy 21 with holoprosencephaly, the fifth case in the literature, is described. The patient also had extracephalic malformations frequently associated with Down syndrome. The possibility of a causal relationship between trisomy 21 and holoprosencephaly is discussed.
\end{abstract}

Key Words holoprosencephaly, trisomy 21, Down syndrome

\section{INTRODUCTION}

Despite the presence of many dysmorphic features in Down syndrome, major malformations produced by trisomy 21 principally involve only two systems, the heart and the gastrointestinal tract. Although structural abnormalities such as reduced brain weight, decreased number and depth of sulci in the cerebral cortices, neuronal heterotopias, and reduced numbers of specific populations of neurons in the cerebral cortices have been frequently observed, the results of neuropathologic study in the majority of patients with Down syndrome are normal. The only gross defect of the brain which has been observed as a result of trisomy 21 is holoprosencephaly, a malformation complex of impaired cleavage of the embryonic forebrain and incomplete midfacial development. Four cases of trisomy 21 with holoprosencephaly have been reported.

We here describe the fifth case with both conditions, the first Japanese case, and discuss the possibility of the causal relationship.

\section{CASE REPORT}

The female newborn was the fourth child of a 33-year-old mother and a 35year-old father, both healthy and nonconsanguineous. The family history was

Received February 18, 1991; Accepted March 29, 1991. 
noncontributory. Three elder siblings were all healthy. The mother's first pregnancy had resulted in a spontaneous abortion at 8 weeks of pregnancy.

At approximately 36 weeks gestation, the patient's mother was evaluated by

A

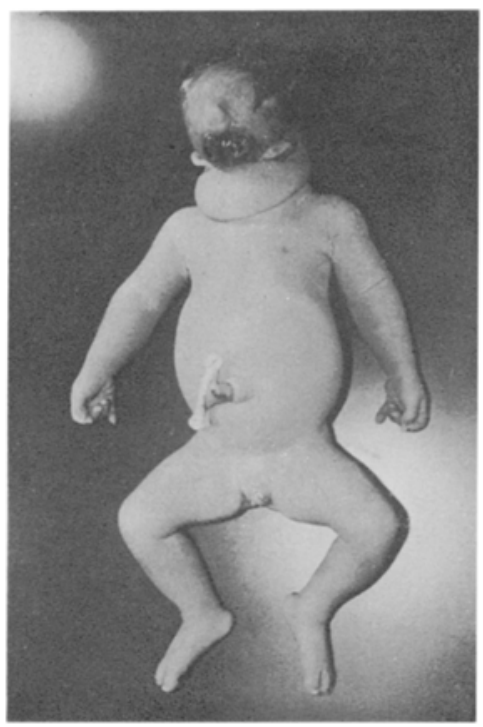

B

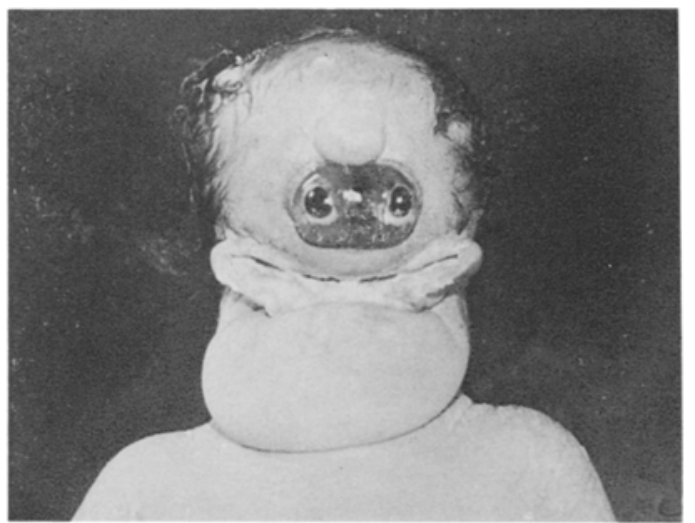

Fig. 1. (A, B) Female newborn showing cyclopia, a supraorbital proboscis, astomia and synotia.

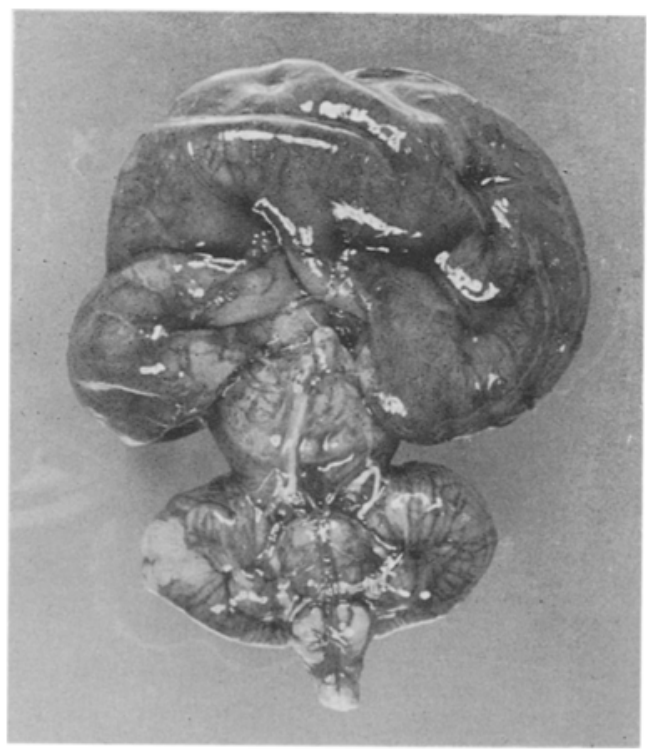

Fig. 2. Alobar holoprosencephaly without separate hemispheres. 
ultrasound, documenting holoprosencephaly in the fetus. At 37 weeks gestation, vaginal delivery of the proposita was induced. The Apgar score was 3 at 1 min. Her weight and length were $2,025 \mathrm{~g}(<5$ th centile) and $44 \mathrm{~cm}(<10$ th centile), respectively. She lived approximately $40 \mathrm{~min}$. She had a single fused eye, a supraorbital proboscis, astomia and synotia (Fig. 1).

Autopsy showed alobar holoprosencephaly (Fig. 2) with an egg-sized dorsal sac in the occipital region and agenesis of hypophysis, cyclopia in one orbit cavity, a soy-bean sized proboscis, astomia with accompanied agnathia, synotia and microglossia, megacolon of the sigmoid colon, hypogenesis of both adrenals, and a ventricular septal defect of about $10 \mathrm{~mm}$ in diameter and persistence of ductus arteriosus in the heart.

Chromosome analyses with GTG banding showed a 47,XX, +21 chromosome constitution in all 50 peripheral lymphocytes examined. The parents had normal karyotypes.

\section{DISCUSSION}

The present case had alobar holoprosencephaly with cyclopia. Besides the holoprosencephaly complex, she had low birth weight and length, megacolon of the sigmoid colon, hypogenesis of both adrenals, and a ventricular septal defest and persistence of ductus arteriosus in the heart. These extracranial features could be considered as manifestations of trisomy 21 . Thus, although holoprosencephaly obscured the craniofacial features of Down syndrome, some malformations frequently associated with chromosomal abnormalities indicated that the present case should be investigated cytogenetically.

Holoprosencephaly is a anomaly in the central nervous system which results from differential disturbance of prosencephalon at three cephalon to five cephalon in the early embryo. There is a spectrum, in decreasing severity, from alobar to semilobar and lobar holoprosencephaly (DeMyer et al., 1964). In alobar holoprosencephaly, an abnormally small forebrain mass with complete failure of formation of the hemispheres is seen. Holoprosencephaly is usually associated with defects of midline craniofacial development, ranging in severity from cyclopia to lesser deformities such as mild hypotelorism or single maxillary central incisor. In cyclopia, the most extreme defect, a single eye globe with varying degrees of doubling of intrinsic ocular structures, arrhinia and a blind-ending proboscis located above the median eye are found.

Etiologically, holoprosencephaly is extremely heterogenous and has been reported in autosomal dominant (Seidlitz et al., 1983) and recessive forms (Cohen and Gorlin, 1969), as part of various syndromes, as a result of infection by cytomegalovirus (Byrne et al., 1987), in infants of diabetic mothers, and in association with chromosomal abnormalities. About two-thirds of the cases of holoprosencephaly show chromosomal abnormalities (Moerman et al., 1988). Structural and 
numerical aberrations of chromosome 13 and 18 are the most frequent chromosomal abnormalities found in individuals with holoprosencephaly. There are numerous case reports with trisomy 13 , duplications or deletions of different regions on $13 \mathrm{q}$ and ring chromosome 13. Deletion of $18 \mathrm{p}$ is also a frequent cause of this craniofacial malformation complex. Holoprosencephaly is not frequently found in patients with trisomy 18 , though there are a number of case reports.

In contrast to trisomies 13 and 18 , holoprosencephaly has been extremely rarely found in patients with trisomy 21 ; only four cases have been reported so far. The first case, reported by Pi et al. in 1980, was born to a mildly diabetic mother and had semilobar holoprosencephaly and duodenal atresia. Pi et al. (1980) asserted a causal relationship between trisomy 21 and holoprosencephaly, and also suggested an increased susceptibility to the developmental defect due to the association of the pregnancy with very mild diabetes. The second case of Down syndrome with holoprosencephaly was reported by Urioste et al. in 1988. The patient had alobar holoprosencephaly and was born to a nondiabetic mother. They supported the opinion in favor of a causal relationship between trisomy 21 and holoprosencephaly, because of the very low probability of concurrence of both abnormalities by chance in the same patient-about 1 in 11 million calculated from a rate of trisomy 21 of $1 / 645$ and a rate of holoprosencephaly of $1 / 18,000$ (Martinez-Frias, 1989). On the other hand, Epstein et al. (1988), reporting the third case of trisomy 21 with semilobar holoprosencephaly, submitted that the presentation of the probabilities by Urioste et al. (1988) was misleading because the number of cases (three) reported in the United States and Europe during 8 years had hardly exceeded the number expected purely by chance. In 1990, Corsello et al. presented the fourth case of trisomy 21 with holoprosencephaly. However, they had no discussion about the causal relationship between the two conditions.

The present case is the first case reported in Japan. The birth defects monitoring programs in Japan show that the incidence of Down syndrome is between $1 / 1,100$ and $1 / 1,600$ and thatof holoprosencephaly between $1 / 16,000$ and $1 / 50,000$ (Kuroki and Konishi, 1984). Therefore, the probability of concurrence of trisomy 21 and holoprosencephaly in the same patient purely by chance is expected to be about 1 in 18-80 million in Japan. With an annual birth rate of about 1.5 million infants in Japan for the last 10 years, one infant with both Down syndrome and holoprosencephaly would be expected every 10 or more years in Japan by chance. This figure is, of course, assuming that the complication of both conditions does not cause more fetal losses than either single abnormality does. The very small number of such cases, only one in Japan and five in the world for the 11 years since the first documented case was reported, might be evidence against a causal relationship between the two conditions. Although the question as to whether trisomy 21 increases susceptibility to holoprosencephaly is still open, at present it seems to be reasonable to conclude that trisomy 21 does not cause gross brain anomalies, including holoprosencephaly. 


\section{REFERENCES}

Byrne, P.J., Silver, M.M., Gilbert, J.M., Cadera, W. and Tanswell, A.K. 1987. Cyclopia and congenital cytomegalovirus infection. Am. J. Med. Genet. 28: 61-65.

Cohen, M.M., Jr, and Gorlin, R.J. 1969. Genetic considerations in a sibship of cyclopia and clefts. Birth Defects Orig. Art. Ser. V(2): 113-118.

Corsello, G., Buttitta, P., Cammarata, M., Presti, A.L., Maresi, E., Zumpani, L. and Giuffré, L. 1990. Holoprosencephaly: Examples of clinical variability and etiologic heterogeneity. $A m$. J. Med. Genet. 37: 244-249.

DeMyer, W., Zeman, W. and Palmer, C.G. 1964. The face predicts the brain: Diagnostic significance of median facial anomalies for holoprosencephaly (arhinencephaly). Pediatrics 34: 256-263.

Epstein, C.J., Seto, S. and Golabi, M. 1988. Chance vs. causality in the association of Down syndrome and holoprosencephaly. Am, J. Med. Genet. 30: 939-942.

Kuroki, Y. and Konishi, H. 1984. Current status and perspectives in the Kanagawa birth defects monitoring program (KAMP). Cong. Anom. 24: 385-393.

Martinez-Frias, M.L. 1989. Association of holoprosencephaly and Down syndrome. Am. $J$. Med. Genet, 32: 435.

Moerman, P., Fryns, J.-P., van der Steen, K., Kleczkowska, A. and Lauweryns, J. 1988. The pathology of trisomy 13 syndrome: A study of 12 cases. Hum. Genet. 80: 349-356.

Seidlitz, G., Kadow, I., Theel, I., Pietsch, P., Rudel, J., Schneider, K. and Schroeter, C. 1983. Genetische Aspekte und humangenetische Beratung der Holoprosencephalie. Dt. Gesundh.Wesen 38: 665-669.

Pi, S.-Y., Fineman, R.M., Wing, S.D., Grunnet, M. and Chan, G. 1980. Holoprosencephaly in a Down syndrome child. Am. J. Med. Genet. 5: 201-206.

Urioste, M., Valcarcel, E., Gomez, M.A., Pinel, I., Garcia de León, R., Diaz de Bustamante, A., Tebar, R. and Martinez-Frias, M.L. 1988. Holoprocencephaly and trisomy 21 in a child born to a nondiabetic mother. Am. J. Med. Genet. 30: 925-928. 